University of Nebraska - Lincoln

DigitalCommons@University of Nebraska - Lincoln

Faculty Papers and Publications in Animal

Science

Animal Science Department

January 1998

\title{
Comparison of Sire Breed Solutions for Growth Traits Adjusted by Mean Expected Progeny Differences to a 1993 Base
}

\author{
K. L. Barkhouse \\ University of Nebraska-Lincoln \\ L. Dale Van Vleck \\ University of Nebraska-Lincoln, dvan-vleck1@unl.edu \\ Larry V. Cundiff \\ University of Nebraska-Lincoln, Icundiff2@unl.edu \\ D. S. Buchmann \\ Oklahoma State University, Stillwater \\ D. M. Marshall \\ South Dakota State University, Brookings
}

Follow this and additional works at: https://digitalcommons.unl.edu/animalscifacpub

Part of the Animal Sciences Commons

Barkhouse, K. L.; Van Vleck, L. Dale; Cundiff, Larry V.; Buchmann, D. S.; and Marshall, D. M., "Comparison of Sire Breed Solutions for Growth Traits Adjusted by Mean Expected Progeny Differences to a 1993 Base" (1998). Faculty Papers and Publications in Animal Science. 271.

https://digitalcommons.unl.edu/animalscifacpub/271

This Article is brought to you for free and open access by the Animal Science Department at DigitalCommons@University of Nebraska - Lincoln. It has been accepted for inclusion in Faculty Papers and Publications in Animal Science by an authorized administrator of DigitalCommons@University of Nebraska - Lincoln. 


\title{
Comparison of Sire Breed Solutions for Growth Traits Adjusted by Mean Expected Progeny Differences to a 1993 Base $^{1,2}$
}

\author{
K. L. Barkhouse*, L. D. Van Vleck ${ }^{\dagger, 3}$, L. V. Cundiff, D. S. Buchanan\$, \\ and D. M. Marshall \\ *Animal Sciences Department, University of Nebraska, Lincoln 68583-0908; \\ Roman L. Hruska U.S. Meat Animal Research Center, ARS, USDA, †Lincoln, NE 68583-0908 \\ and ₹Clay Center, NE 68933; sOklahoma State University, Stillwater 74078-0425; \\ and "South Dakota State University, Brookings 57007
}

\begin{abstract}
Records on growth traits were obtained from five Midwestern agricultural experiment stations as part of a beef cattle crossbreeding project (NC-196). Records on birth weight (BWT, $n=3,490$ ), weaning weight (WWT, $\mathrm{n}=3,237$ ), and yearling weight (YWT, $\mathrm{n}=1,372$ ) were analyzed within locations and pooled across locations to obtain estimates of breed of sire differences. Solutions for breed of sire differences were adjusted to the common base year of 1993. Then, factors to use with within-breed expected progeny differences (E PD) to obtain acrossbreed EPD were calculated. These factors were compared with factors obtained from similar analyses of records from the U. S. Meat Animal Research Center (MARC). Progeny of Brahman sires mated to Bos taurus cows were heaviest at birth and among the

lightest at weaning. Simmental and Gelbvieh sires produced the heaviest progeny at weaning. Estimates of heritability pooled across locations were .34, .19, and .07 for BWT, WWT, and YWT, respectively. Regression coefficients of progeny performance on EPD of sire were $1.25 \pm .09, .98 \pm .13$, and $.62 \pm .18$ for BWT, WWT, and YWT, respectively. Rankings of breeds of sire generally did not change when adjusted for sire sampling. Rankings were generally similar to those previously reported for MARC data, except for Limousin and Charolais sires, which ranked lower for BWT and WWT at NC-196 locations than at MARC. Adjustment factors used to obtain across-breed EPD were largest for Brahman for BWT and for Gelbvieh for WWT. The data for YWT allow only comparison of Angus with Simmental and of Gelbvieh with Limousin.
\end{abstract}

Key Words: Beef Cattle, Breeds, Breeding Value, Growth

@1998 American Sociey of Animal Science. All rights reserved.

J. Anim. Sci. 1998. 76:2287-2293

\section{Introduction}

Optimal use of crossbreeding requires a method of selecting animals of different breeds based on comparisons across breeds. Expected progeny differences (EPD) currently used to compare animals on a

\footnotetext{
${ }^{1}$ Published as paper no. 11671, J ournal Ser., Nebraska Agric. Res. Div., Univ. of Nebraska, Lincoln 68583-0908.

${ }^{2}$ Data for this report came from experiment stations represented in regional project NC-196; I owa State Univ., Michigan State Univ., Oklahoma State Univ., South Dakota State Univ., and Louisiana State Univ.

${ }^{3}$ To whom correspondence should be addressed.

Received September 9, 1996.

Accepted August 30, 1997.
}

within-breed basis are not appropriate when comparing animals of different breeds. Previous reports on across-breed EPD have come from data collected at the U. S. Meat Animal Research Center (MARC) in Clay Center, Nebraska. Those results, however, should be compared with results of similar analyses on data from other sources.

Growth traits from five experiment stations participating in a regional beef cattle project (NC-196) have been recorded and analyzed within stations; however, comprehensive analyses involving data from all stations have not previously been performed. Such analyses could provide estimates of breed of sire differences for growth traits that then could be used to obtain across-breed EPD. The objective of this study was to estimate breed of sire differences for growth traits and to obtain factors to add to within-breed EPD to allow comparisons of sire EPD across breeds for growth traits. 
Table 1. Number of records for birth weight (BWT), weaning weight (WWT), and yearling weight (YWT) by station

\begin{tabular}{lrrr}
\hline \hline Station & BWT & WWT & YWT \\
\hline Iowa & 1,229 & 1,016 & 879 \\
Louisiana & 574 & 538 & 0 \\
Michigan & 357 & 354 & 0 \\
Oklahoma & 517 & 517 & 493 \\
South Dakota & 813 & 813 & 0 \\
Total & 3,490 & 3,238 & 1,372 \\
\hline
\end{tabular}

\section{Materials and Methods}

Records on growth traits were obtained from lowa State University (IA), Louisiana State University (LS), Michigan State University (MI), Oklahoma State University $(O K)$, and South Dakota State University (SD). The numbers of records, by experiment station, for birth (BWT), weaning (205 d; WWT), and yearling (365 d) weights (YWT) are given in Table 1. Table 2 shows the numbers of sires and progeny with WWT records by breed of sire and station. Brahman, Charolais, Tarentaise, and Salers sires were used only at LS. Yearling weights were available only at IA for Angus and Simmental and at OK for Limousin and Gelbvieh.

\section{Iowa State University}

Data from four calf crops (1991 through 1994) were obtained from IA. Angus and Simmental sires were mated to crossbred dams with varying amounts of Angus, Simmental, Holstein, Brown Swiss, and Charolais inheritance (R. L. Willham, personal communication). Crossbred calves were produced in two locations and had an average heterozygosity of $62 \%$.

\section{Louisiana State University}

Crossbred calves were produced and raised through weaning at Louisiana State University to be finished at Kansas State University between 1989 and 1993. Five breeds of sire (Angus, Charolais, Gelbvieh, Polled Hereford, and Simmental) were mated to rotational-cross cows with varying percentages of Angus, Brahman, Charolais, and Hereford inheritance (Andries et al., 1994). Brahman sires were mated to Angus, Charolais, and Hereford dams. Gelbvieh and Simmental sires were also mated to Brahman $x$ Angus, Brahman $\times$ Charolais, and Brahman $\times$ Hereford dams. Matings produced crossbred progeny with expected breed heterozygosity ranging from 66 to $100 \%$.

\section{Michigan State University}

Growth records were obtained from calves produced at MI between 1983 and 1991 (Cunningham et al., 1985). Five breeds of sire (Angus, Polled Hereford, Simmental, Gelbvieh, and Shorthorn) were mated to dams with varying amounts of Angus, Charolais, Gelbvieh, Her eford, Holstein, Shorthorn, and Simmental inheritance. Purebred Angus and Polled Hereford calves and crossbred calves with heterozygosity ranging from 25 to $100 \%$ were produced.

\section{Oklahoma State University}

Data were obtained on calf crops born between 1978 and 1986. Five breeds of sire were mated to seven $F_{1}$ cow groups (Hereford-Angus/Angus-Hereford, Simmental-Angus, Simmental-Hereford, Brown Swiss-Angus, Brown Swiss-Hereford, J ersey-Angus, and J erseyHereford; Marshall et al. 1985). In 1976 and 1977, calves were sired by Brahman and Charolais sires. The 1978 through 1981 calves were sired by Charolais and Limousin bulls, and calves born between 1982 and 1985 were sired by Limousin and Gelbvieh bulls. All matings resulted in calves that were $100 \%$ heterozygous.

\section{South Dakota State University}

Records were collected on calves born between 1975 and 1990. Seven breeds of sire (Angus, Charolais,

Table 2. Number of sires (S) and progeny (P) having weaning weights by breed of sire

\begin{tabular}{|c|c|c|c|c|c|c|c|c|c|c|}
\hline \multirow[b]{2}{*}{ Breed of sire } & \multicolumn{2}{|c|}{ lowa } & \multicolumn{2}{|c|}{ Louisiana } & \multicolumn{2}{|c|}{ Michigan } & \multicolumn{2}{|c|}{ Oklahoma } & \multicolumn{2}{|c|}{ South Dakota } \\
\hline & $\mathrm{S}$ & $P$ & $\mathrm{~S}$ & $P$ & $\mathrm{~S}$ & $P$ & $\mathrm{~S}$ & $P$ & $\mathrm{~S}$ & $P$ \\
\hline P. Hereford & $-{ }^{a}$ & - & 10 & 34 & 21 & 172 & - & - & 19 & 468 \\
\hline Angus & 24 & 781 & 11 & 42 & 4 & 57 & - & - & 8 & 110 \\
\hline Brahman & - & - & 5 & 31 & - & - & - & - & - & - \\
\hline Simmental & 4 & 235 & 12 & 133 & 12 & 56 & - & - & 11 & 152 \\
\hline Limousin & - & - & - & - & - & - & 22 & 368 & 2 & 4 \\
\hline Charolais & - & - & 11 & 62 & - & - & - & - & - & - \\
\hline Gelbvieh & - & - & 31 & 236 & 9 & 69 & 9 & 149 & - & - \\
\hline Tarentaise & - & - & - & - & - & - & - & - & 9 & 38 \\
\hline Salers & - & - & - & - & - & - & - & - & 7 & 41 \\
\hline Total & 28 & 1016 & 80 & 538 & 46 & 354 & 31 & 517 & 56 & 813 \\
\hline
\end{tabular}

aDash indicates breed of sire not used. 
Limousin, Polled Hereford, Salers, Simmental, and Tarentaise) were mated to purebred, $\mathrm{F}_{1}$, and rotational cross cows with differing percentages of Angus, Hereford, Simmental, and Tarentaise inheritance (Marshall et al., 1990). Calves were raised at two locations and had an average heterozygosity of $61 \%$.

\section{Statistical Analyses}

All stations reported BWT and WWT records. Only OK and IA reported YWT. Analyses on all traits were performed by station because models were different for different stations and fixed effects were not crossclassified across stations. The basic goal was to obtain breed of sire solutions that were pooled across stations. There were no known ties across stations. Only records of progeny of bulls with a breed association EPD were included in the analyses because the breed of sire solutions should be adjusted to a common year across breeds, which is possible only for bulls with EPD (N otter and Cundiff, 1991). Single trait analyses were completed with a sire model using a derivative-free restricted maximum likelihood (MTDFREML) program to estimate variance components and breed of sire effects (Boldman et al., 1993). Models included a fixed effect for breed of sire as well as a fixed subclass factor that included sex of calf and age of dam for all stations, and location, management, and rearing codes as needed for each station (Table 3). For LS, OK, and SD, the subclass factor also included breed of dam. For MI and I A, fixed covariates representing the fraction of genes from each breed contributing to the dam were used in place of a breed of dam class factor due to the large number of distinct types of crossbred cows. The model also included fixed covariates for Julian birth date and fraction of heterozygosity of the calf. Random effects were year of birth and sire. Heterozygosity could not be determined for most dams, so that effect could not be included in the model. Heterozygosity was not included in the model for OK records due to $100 \%$ heterozygosity for all progeny.

Records of progeny from registered sires with EPD were used in analyses similar to previous analyses of data from the Germ Plasm Evaluation (GPE) program conducted at the U. S. MARC (Notter and Cundiff, 1991; Cundiff, 1993; Núñez-Dominguez et al., 1993; Barkhouse et al., 1994, 1995). Estimates of breed of sire solutions contrasted from Angus and the sampling covariance matrices were obtained for each station. Breed of sire solutions and variances were pooled over stations using a generalized least squares procedure with contrasts weighted by inverses of the sampling covariance matrices. Once pooled, breed of sire solutions were added to the raw mean for Angus to obtain "least squares means" for each breed of sire.

Analyses to obtain regression coefficients for progeny performance on sire EPD reported in 1995 were done by station using the models described
Table 3. Fixed effects included in subclass variables within station

\begin{tabular}{ll}
\hline \hline Station & Subclass effects \\
\hline I owa & Sex of calf, age of dam, location \\
Louisiana & Breed of dam, sex of calf, age of dam \\
Michigan ${ }^{a, b}$ & Age of dam, rearing code, pen number \\
Oklahoma & Breed of dam, sex of calf, age of dam \\
South Dakota & Breed of dam, sex of calf, age of dam, location \\
\hline
\end{tabular}

aBreed of dam represented by covariates for each breed contributing to the cow.

bex of calf $=$ steer.

above, omitting the random sire effect. An additional covariate for EPD of the sire was used (Notter and Cundiff, 1991). Regression coefficients were obtained for each station using the MIXED procedure of SAS (1989). Estimates of regression coefficients and standard errors were obtained for each station, pooled over all stations, and coefficients were tested against the theoretical expected regression coefficient of 1.0. Homogeneity of regression coefficients across breed of sire and each subclass variable was tested by including the interaction between EPD and the effect of interest in the model. Breed-of-sire means were adjusted for sire sampling as described by Notter and Cundiff (1991). Mean EPD from 1995 evaluations needed for adjustments for sire sampling were obtained from the 1995 national cattle evaluations for each breed (Table 4). Adjustment factors to adjust within-breed EPD to allow comparisons across breeds were obtained as described by Cundiff $(1993,1994)$.

Similar analyses on growth trait data from the GPE program at MARC were reported by Barkhouse et al. (1995). Data from MARC represented more data than were available from the NC-196 stations combined. Records were not pooled with MARC data to avoid overwhelming estimates of breed of sire differences with the MARC data and so that results could be compared with those based on MARC data.

\section{Results and Discussion}

Sire effects generally accounted for less than $16 \%$ of the total variance in BWT, resulting in estimates of heritabilities ranging from .00 to .62 , with an average (weighted by number of records) of .32 (Table 5). For WWT, sire variance was less than $4 \%$ of the total variance for all stations except MI, for which sire effects accounted for $22 \%$ of total variance. Estimates of heritabilities for WWT ranged from .05 to .90, with a weighted average of .20. Sire variance represented less than $2 \%$ of the total variance for YWT, resulting in estimates of heritability under .10. Standard errors of estimates within the five NC-196 stations are expected to be large due to the small data sets. Year of birth accounted for less than $11 \%$ of the total variance 
Table 4. Mean EPD (kg) of animals born in 1993 from 1995 National Cattle Evaluation for each breed

\begin{tabular}{lrrr}
\hline \hline Breed of sire & BWT & WWT & YWT \\
\hline P. Hereford & 1.41 & 10.61 & 17.92 \\
Angus & 1.45 & 11.29 & 18.87 \\
Brahman & .48 & 3.78 & 6.43 \\
Simmental & .18 & 3.22 & 5.53 \\
Limousin & .54 & 2.95 & 5.44 \\
Charolais & .72 & 4.07 & 6.13 \\
Gelbvieh & .09 & 2.04 & 3.86 \\
Tarentaise & 1.14 & 4.30 & 6.89 \\
Salers & .36 & 3.63 & 6.08 \\
\hline
\end{tabular}

for BWT at all stations. For WWT and YWT, birth year accounted for as much as 47 and $42 \%$ of the total variance, respectively.

Breed of sire solutions and standard errors pooled over stations are given in Table 6 . Solutions are expressed as differences from Angus. F or all traits, solutions from NC-196 data were somewhat different from those from MARC data and may be partially due to differences in sires sampled. Brahman and Simmental sires produced the heaviest progeny at birth, and Limousin sires produced the lightest progeny having relatively smaller BWT solutions than progeny of Limousin sires used at MARC. Progeny of Gelbvieh and Simmental sire breeds had the largest WWT solutions, which were significantly different from Angus $(P<.05)$, and progeny of sires of the Salers breed had the smallest WWT relative to Angus. Tarentaise sires used in NC-196 produced relatively heavier progeny at weaning than Tarentaise sires used at MARC (Notter and Cundiff, 1991; Cundiff, 1993; Núñez-Dominguez et al., 1993; Barkhouse et al., 1994). Although Salers sires produced among the heaviest progeny at birth, the WWT solution for Salers was the smallest for NC-196, which was not consistent with the relatively high ranking of the Salers breed based on sires used at MARC.

The data did not allow estimates of differences among all breeds for YWT. The only estimable contrasts for breeds of sire were between Angus and Simmental at IA and between Gelbvieh and Limousin at OK.

Table 5. Estimates of heritabilities for birth weight (BWT), weaning weight (WWT), and yearling weight (YWT) by station and pooled across stations

\begin{tabular}{lccc}
\hline \hline Station & BWT & WWT & YWT \\
\hline Iowa & .48 & .16 & .06 \\
Louisiana & .14 & .16 & $-{ }^{\mathrm{a}}$ \\
Michigan & .00 & .90 & - \\
Oklahoma & .22 & .05 & .08 \\
South Dakota & .43 & .05 & - \\
NC196 (pooled) & .32 & .20 & .07 \\
\hline
\end{tabular}

aDash indicates station not reporting YWT.
Standard errors of differences from Angus from MARC analyses were generally approximately onehalf to one-third of those from NC-196, except for the Simmental comparisons. Thus, most comparisons of breed solutions with Angus are not significantly different from zero. Yet the best prediction of difference between two bulls of different breeds would use the estimated adjustment factors regardless of the standard errors of solutions for breed effects. Pooling NC-196 and MARC breed of sire solutions weighted by inverses of the matrices of contrast variances would result in estimates similar to those from MARC.

Solutions for breed of sire would be confounded with breed of sire $\times$ location interaction effects and would be averaged over lactations with the pooling process. However, several breeds were at only one location: Brahman and Charolais at LS and Tarentaise and Salers at SD, with few sires or progeny at those locations. Limousin were essentially only at OK with several sires and progeny but were compared with only about half as many Gelbvieh.

Coefficients and standard errors for regression of progeny birth weight on BWT EPD of the sire are given in Table 7. Standard errors are expected to be underestimated because the regression variable, EPD of the sire, is not measured with perfect accuracy. The standard error indicated that the regression coefficient for IA was larger than $1.0(\mathrm{P}<.05)$, and the regression coefficient for LS was smaller than 1.0 ( $P<$ $.05)$. These results suggest that there might be some reranking of sires for BWT EPD at IA and LS. Regression coefficients for the remaining stations did not differ significantly from 1.0. The pooled regression coefficient for BWT was significantly greater than 1.0 (1.25 \pm .09$)$. This coefficient was heavily influenced by data from IA, which represented $35 \%$ of BWT records. The current estimate is larger than previous estimates ranging from .84 to 1.12 (Notter and Cundiff, 1991; Notter and Mahrt, 1991; Wright and

Table 6. Breed of sire solutions and standard errors (Angus as constraint) for birth weight (BWT, kg), weaning weight (WWT, kg), and yearling weight (YWT, kg) pooled across stations

\begin{tabular}{lccc}
\hline \hline Breed of sire & \multicolumn{1}{c}{ BWT } & WWT & YWT \\
\hline P. Hereford & $.89 \pm 1.02$ & $4.20 \pm 4.39$ & $-^{\mathrm{a}}$ \\
Angus & 0 & 0 & $0^{\mathrm{b}}$ \\
Brahman & $6.61 \pm 1.68$ & $-7.69 \pm 7.82$ & - \\
Simmental & $2.91 \pm .79$ & $9.48 \pm 3.43$ & $1.27 \pm 5.99^{\mathrm{b}}$ \\
Limousin & $-2.03 \pm 1.32$ & $-7.79 \pm 5.04$ & $0^{\mathrm{c}}$ \\
Charolais & $.42 \pm 1.35$ & $-5.75 \pm 6.68$ & - \\
Gelbvieh & $1.05 \pm 1.05$ & $9.52 \pm 5.11$ & $12.92 \pm 5.44^{\mathrm{c}}$ \\
Tarentaise & $1.61 \pm 1.66$ & $-.74 \pm 7.34$ & - \\
Salers & $1.71 \pm 2.00$ & $-10.85 \pm 8.96$ & - \\
\hline
\end{tabular}

aDash indicates breeds without YWT records.

bOnly difference between Angus and Simmental estimable from lowa.

'Only difference between Gelbvieh and Limousin estimable from Oklahoma. 
Table 7. Estimates of regression coefficients $(\mathrm{kg} / \mathrm{kg})$ of progeny performance on EPD of the sire for birth weight (BWT), weaning weight (WWT), and yearling weight (YWT) by station and pooled across stations

\begin{tabular}{lccc}
\hline \hline Station & BWT & WWT & YWT \\
\hline Iowa & $1.5 \pm .1^{\mathrm{b}}$ & $1.3 \pm .3$ & $.5 \pm .3$ \\
Louisiana & $.3 \pm .2^{\mathrm{b}}$ & $1.0 \pm .3$ & $-{ }^{\mathrm{a}}$ \\
Michigan & $.6 \pm .4$ & $.2 \pm .7$ & - \\
Oklahoma & $1.2 \pm .3$ & $1.0 \pm .3$ & $.7 \pm .2$ \\
South Dakota & $1.5 \pm .3$ & $.7 \pm .3$ & - \\
NC196 (pooled) & $1.25 \pm .09^{\mathrm{b}}$ & $.98 \pm .13$ & $.62 \pm .18^{\mathrm{b}}$ \\
\hline
\end{tabular}

${ }^{a}$ Dash indicates station not reporting YWT.

${ }^{b}$ Regression coefficient is different from $1.0(P<.05)$.

Pollak, 1991; Cundiff, 1993; Núñez-Dominguez et al., 1993; Barkhouse et al., 1994).

Regression coefficients for WWT did not differ significantly from 1.0 at any station and ranged from .2 to 1.3. The pooled coefficient was .98 \pm .13 , indicating that WWT EPD effectively predicts differences in progeny weights at weaning when averaged over numerous sires and progeny. This result is consistent with previous estimates ranging from .6 to 1.0 (Notter and Cundiff, 1991; Notter and Mahrt, 1991; Wright and Pollak, 1991; Núñez-Dominguez et al., 1993; Cundiff, 1993; Barkhouse et al., 1994).

Regression coefficients for YWT on sire EPD did not significantly differ from 1.0 for IA or OK, although both estimates were less than 1.0. The pooled regression coefficient for progeny YWT on EPD of the sire was significantly less than unity $(.62 \pm .18)$, which indicates that YWT EPD of the sire is only partially reflected in crossbred progeny at IA and OK for the breeds represented at those stations. This estimate agrees with that reported by Wright and Pollak (1991), but it is smaller than estimates from MARC data ranging from 1.14 to 1.66 reported by Notter and Cundiff (1991), Cundiff (1993), Núñez-Dominguez et al. (1993), and Barkhouse et al. (1994).

Standard errors of regression coefficients by station and breed were large due to the small numbers of records. Regression coefficients for BWT, WWT, and YWT were not significantly different across breeds of sire for all stations except IA, for which Simmental had a significantly larger regression coefficient than Angus for WWT and YWT. Regression coefficients across subclass variables were not significantly different for all stations and traits and generally did not differ significantly from 1.0 except for IA, for which regression coefficients by sex of calf were significantly different from each other and from 1.0 for BWT, indicating that sires used for crossbreeding may be ranked differently depending on sex of calf. Previous tests of homogeneity across breed of dam, age of dam, and sex were generally not rejected (Notter and Cundiff, 1991; Cundiff, 1993; Núñez-Dominguez et al., 1993; Barkhouse et al., 1994).

Pooled regression coefficients (Table 7) and mean EPD of NC-196 sires (Table 8) were used to adjust NC-196 breed of sire means (pooled solution + pooled raw Angus mean) to a 1993 base (Table 9) as described by Notter and Cundiff (1991). Rankings of breeds of sire for BWT, WWT, and YWT before and after adjustment were relatively constant.

Adjustment factors (Cundiff, 1994) for withinbreed EPD are given in Table 10. Angus was considered the base breed. Brahman sires required the largest adjustment for BWT, whereas Limousin sires required the smallest. Gelbvieh sires had the largest adjustment for WWT. Barkhouse et al. (1994) reported larger adjustments for EPD of Limousin and Charolais sires from MARC analyses for BWT and WWT. In the analysis of NC-196 data, the difference between adjusted BWT means of progeny from Charolais or Limousin sires and progeny from Angus sires was smaller, reducing the total adjustment, relative to that from MARC data.

The largest differences in adjustment factors between NC-196 and MARC data for WWT are for Brahman (.62 for NC-196 and $18.45 \mathrm{~kg}$ for MARC) and for Charolais (1.51 and $19.50 \mathrm{~kg})$. Only LS contributed to those comparisons with limited number of sires or progeny for Angus, Brahman, and

Table 8. Mean weighted EPD $(\mathrm{kg})$ and BIF accuracies for birth weight (BWT), weaning weight (WWT), and yearling weight (YWT)

\begin{tabular}{|c|c|c|c|c|c|c|}
\hline \multirow[b]{2}{*}{ Breed of sire } & \multicolumn{2}{|c|}{ BWT } & \multicolumn{2}{|c|}{ WWT } & \multicolumn{2}{|c|}{ YWT } \\
\hline & EPD & ACC & EPD & $\mathrm{ACC}$ & EPD & $\mathrm{ACC}$ \\
\hline P. Hereford & .95 & .76 & 8.32 & .77 & $-a$ & - \\
\hline Angus & 1.35 & .92 & 13.32 & .91 & 23.36 & .88 \\
\hline Brahman & .66 & .60 & 3.33 & .56 & - & - \\
\hline Simmental & .34 & .75 & 4.82 & .75 & 13.07 & .74 \\
\hline Limousin & .08 & .92 & -1.22 & .89 & -1.86 & .86 \\
\hline Charolais & .69 & .61 & 4.40 & .60 & - & - \\
\hline Gelbvieh & .26 & .62 & 1.44 & .57 & 3.05 & .51 \\
\hline Tarentaise & .31 & .90 & .90 & .89 & - & - \\
\hline Salers & -.59 & .77 & -2.35 & .70 & - & - \\
\hline
\end{tabular}

aDash indicates breed not in analysis. 
Table 9. Breed of sire means (kg) unadjusted (U) and adjusted (ADJ) to a common base year (1993) for birth weight (BWT), weaning weight (WWT), and yearling weight (YWT)

\begin{tabular}{|c|c|c|c|c|c|c|}
\hline \multirow[b]{2}{*}{ Breed of sire } & \multicolumn{2}{|c|}{ BWT } & \multicolumn{2}{|c|}{ WWT } & \multicolumn{2}{|c|}{ YWT } \\
\hline & U & ADJ & u & $A D J$ & U & ADJ \\
\hline P. Hereford & 37.95 & 38.54 & 210.8 & 213.1 & - & - \\
\hline Angus & 37.06 & 37.19 & 206.6 & 204.6 & $419.7^{\mathrm{a}}$ & $417.0^{\mathrm{a}}$ \\
\hline Brahman & 43.67 & 43.46 & 198.9 & 199.4 & - & - \\
\hline Simmental & 39.97 & 39.76 & 216.1 & 214.5 & $421.0^{\mathrm{a}}$ & $416.3^{\mathrm{a}}$ \\
\hline Limousin & 35.03 & 35.60 & 198.8 & 202.9 & $413.6^{b}$ & $418.1^{b}$ \\
\hline Charolais & 37.48 & 37.50 & 200.9 & 200.5 & - & - \\
\hline Gelbvieh & 38.11 & 37.89 & 216.1 & 216.7 & $426.5^{b}$ & $427.0^{b}$ \\
\hline Tarentaise & 38.66 & 39.69 & 205.9 & 209.2 & - & - \\
\hline Salers & 38.77 & 39.97 & 195.8 & 201.6 & - & - \\
\hline
\end{tabular}

aOnly Angus vs Simmental difference is estimable from Iowa.

bOnly Limousin vs Gelbvieh difference is estimable from Oklahoma.

Charolais. Thus, whether the differences between LS and MARC are due to sampling variance or due to breed $\times$ location interaction cannot be determined. Significant genotype $\times$ location interactions have been reported for birth and weaning weights in temperate vs subtropical environments between lines of Hereford cattle (Burns et al., 1979) and between Bos taurus and Bos indicus breeds (Olson et al., 1991).

Yearling weight information was not available except for two breeds (Angus and Simmental) compared at IA and two breeds (Limousin and Gelbvieh) compared at Oklahoma. The Limousin-Gelbvieh adjustment factor is similar to that from MARC data, but the Angus-Simmental factor is considerably different for YWT, although similar for BWT and WWT, which included comparisons at three other stations. Reasons for the difference in comparisons at IA and MARC (12.6 and $40.6 \mathrm{~kg}$ ) are not obvious, but the difference suggests some kind of management $\times$ breed interaction, although sampling of only four sires at IA may be a reason. The differences in breed of sire solutions more than doubled between IA and MARC when adjusted for genetic sampling because the average EPD for YWT of bulls used at IA (13.1 kg) was different for that of bulls used at MARC $(-11.9$ $\mathrm{kg}$ ). The difference in regression coefficients (.62 for IA and OK pooled and 1.29 for MARC) also increased slightly this difference in adjustment to the base year of 1993.

Adjustment factors for YWT are not very useful because only Angus can be compared with Simmental or Gelbvieh with Limousin.

\section{Implications}

Within-breed expected progeny differences (EPD) were good indicators of crossbred progeny performance for weaning weight. Average responses in crossbred progeny at the NC-196 stations were greater for birth weight and less for yearling weight than predicted from sire EPD. Breed of sire solutions differed

Table 10. Adjustment factors $(\mathrm{kg})$ for across-breed EPD for birth weight (BWT), weaning weight (WWT), and yearling weight (YWT) by breed of sire (Angus as base) pooled over NC-196 stations

compared with adjustment factors from MARC data

\begin{tabular}{|c|c|c|c|c|c|c|}
\hline \multirow[b]{2}{*}{ Breed of sire } & \multicolumn{3}{|c|}{ NC-196 } & \multicolumn{3}{|c|}{ MARC } \\
\hline & BWT & WWT & YWT & BWT & WWT & YWT \\
\hline P. Hereford & 1.40 & 9.17 & - & 2.0 & 5.68 & - \\
\hline Angus & 0 & 0 & $0^{\mathrm{a}}$ & 0 & 0 & 0 \\
\hline Brahman & 7.67 & .62 & - & 7.14 & 18.45 & - \\
\hline Simmental & 3.84 & 18.01 & $12.6^{\mathrm{a}}$ & 5.32 & 24.91 & 40.6 \\
\hline Limousin & -.68 & 6.65 & $0^{\mathrm{b}}$ & 3.73 & 15.64 & $0^{c}$ \\
\hline Charolais & 1.48 & 1.51 & - & 4.91 & 19.50 & - \\
\hline Gel bvieh & 2.07 & 21.40 & $10.4^{b}$ & 4.95 & 22.00 & $9.3^{c}$ \\
\hline Tarentaise & 3.24 & 9.95 & - & 2.82 & 15.64 & - \\
\hline Salers & 4.30 & 3.04 & - & 3.36 & 13.59 & - \\
\hline
\end{tabular}

${ }^{a}$ Only Angus vs Simmental difference is estimable from lowa.

bOnly Limousin vs Gelbvieh difference is estimable from Oklahoma.

'Difference from Limousin to compare with NC-196. 
somewhat from results from the U.S. Meat Animal Research Center (MARC). Pooling solutions from these data with solutions for MARC might be considered to obtain across-breed adjustments for EPD, but would the effort be worthwhile? The answer seems to be no. No information is available for maternal weaning weight. Information on yearling weight is limited. Three breeds compared at MARC are not compared in the NC-196 data. The number of sires and useful comparisons for the other breeds are limited, so pooling will not change the MARC adjustment factors very much.

\section{Literature Cited}

Andries, K. M., R. R. Schalles, and D. E. Franke. 1994. Estimates of direct and maternal heritability and correlations for birth weight and weaning weight from hybrid cattle. J. Anim. Sci. 72(Suppl.1):148 (Abstr.).

Barkhouse, K. L., L. D. Van Vleck, and L. V. Cundiff. 1994. Breed comparisons for growth and maternal traits adjusted to a 1992 base. Proc. Beef Improvement Federation Annu. Mtg., West Des Moines, IA. pp 197-209.

Barkhouse, K. L., L. D. Van Vleck, and L. V. Cundiff. 1995. Mixed model methods to estimate breed comparisons for growth and maternal traits adjusted to a 1993 base. Proc. Beef Improvement Federation Annu. Mtg., Sheridan, WY. pp 218-239.

Boldman, K. G., L. A. Kriese, L. D. Van Vleck, and S. D. Kachman. 1993. A manual for use of MTDFREML: A set of programs to obtain estimates of variances and covariances. USDA Meat Animal Research Center, Clay Center, NE. p 120.

Burns, W. C., M. Koger, W. T. Butts, O. F. Pahnish, and R. L. Blackwell. 1979. Genotype by environment interaction in Hereford cattle: II. Birth and weaning traits. J . Anim. Sci. 49: 403-409.
Cundiff, L. V. 1993. Breed comparisons adjusted to a 1991 basis using current EPD. Proc. Beef Improvement Federation Annu. Mtg., Asheville, NC. pp 114-123.

Cundiff, L. V. 1994. Procedures for across breed EPD's. Proc. Fourth Genetic Prediction Workshop, BIF. pp 15-29.

Cunningham, B. E., W. T. Magee, and H. D. Ritchie. 1985. Effects of selection and crossbreeding on the cow-calf unit. I. Effects on birth and survival traits. J. Anim. Sci. 61(Suppl. 1):72 (Abstr.).

Marshall, D. M., R. R. Frahm, and L. E. Walters. 1985. Comparisons among two-breed cross cow groups. II. Feedlot and carcass performance of three-breed cross calves. J. Anim. Sci. 61: 856-867.

Marshall, D. M., M. D. Monfore, and C. A. Dinkel. 1990. Performance of Hereford and two-breed rotational crosses of Hereford with Angus and Simmental cattle: I. Calf production through weaning. J . Anim. Sci. 68:4051-4059.

Notter, D. R., and L. V. Cundiff. 1991. Across-breed expected progeny differences: Use of within-breed expected progeny differences to adjust breed evaluations for sire sampling and genetic trend. J. Anim. Sci. 69:4763-4776.

Notter, D. R., and G. S. Mahrt. 1991. An update on the relationship between actual and predicted performance of crossbred calves by divergently selected Polled Hereford sires. J. Anim. Sci. 69(Suppl. 1):218 (Abstr.).

Núñez-Dominguez, R., L. D. Van Vleck, and L. V. Cundiff. 1993. Breed comparisons for growth traits adjusted for within-breed genetic trend using expected progeny differences. J . Anim. Sci. 71:1419-1428.

Olson, T. A., K. Euclides Filho, L. V. Cundiff, M. Koger, W. T. Butts, J r., and K. E. Gregory. 1991. Effects of breed group by location interaction on crossbred cattle in Nebraska and Florida. J. Anim. Sci. 69:104-114

SAS. 1989. User's Guide (Version 6, 4th Ed.). SAS Inst. Inc., Cary, NC.

Wright, D. W., and E. J . Pollak. 1991. Evaluation of Simmental sires producing crossbred calves in two different geographic locations. J. Anim. Sci. 69(Suppl. 1):218 (Abstr.). 